\title{
AS TEORIAS DOS MOVIMENTOS SOCIAIS: UM BALANÇO DO DEBATE*
}

Angela Alonso

As lágrimas de Jesse Jackson no anúncio da eleição de Barack Obama parecem encerrar o ciclo das grandes mobilizações urbanas da segunda metade do século XX. Movimentos sociais, como o pelos direitos civis, de que Jackson foi parte, o feminista e o ambientalista lograram inscrever demandas suas na agenda contemporânea; suas organizações civis se profissionalizaram e muitos de seus ativistas se converteram em autoridades políticas. Essa rotinização do ativismo anda em par, nesse começo de século, com novidades. As mobilizações coletivas ganharam escala global, caráter violento e se concentraram em bandeiras identitárias, compelindo os teóricos a rever suas interpretações.

É que as teorias dos movimentos sociais se constituíram diante de um quadro bastante distinto, o do Ocidente dos anos 1960, quando o próprio termo "movimentos sociais" foi cunhado para designar multidões bradando por mudanças pacíficas ("faça amor, não faça guerra"), desinteressadas do poder do Estado. Até então concentrados em pensar

\footnotetext{
* Sou grata aos comentários de Brasílio Sallum Jr. à versão preliminar deste texto.
} 
revoluções - ou a ausência delas -, os sociólogos produziram três grandes famílias de explicação para os movimentos sociais. Este artigo apresenta essas teorias, apontando, em seguida, as adaptações a que tiveram de se submeter para fazer face à cena contemporânea.

\section{A era clássica das teorias dos movimentos sociais}

Dos anos 1930 a 1960, a sociologia lançou baldes de água fria nas teorias da revolução. Autores muito heterogêneos, como Riesman e Adorno, por exemplo, confluíram para teorias da desmobilização política, cuja chave explicativa estava na cultura, em correlações entre estrutura da personalidade e estrutura da sociedade. $\mathrm{O}$ argumento disseminado era que o individualismo exacerbado da sociedade moderna teria produzido personalidades narcísicas, voltadas para a autossatisfação e de costas para a política. Dado o caráter cômodo da dominação no capitalismo tardio ou

50 na sociedade de massa, operada via consumo e afinada com o padrão dominante de individuação, a mobilização coletiva eclodiria apenas como irracionalidade ou, conforme Smelser, como explosão reativa de frustrações individuais, que as instituições momentaneamente não lograriam canalizar. De uma maneira ou de outra, a explicação tinha pilares psicossociais, amparando-se em emoções coletivas, e tom sombrio, ressoando o contexto de avanço dos regimes totalitários.

A tese da desmobilização, contudo, foi posta à prova pela mudança de cenário. Nos anos 1960, tanto na Europa, sede do totalitarismo, quanto nos Estados Unidos, afinal a pátria da sociedade de massas, ressurgiram mobilizações. Alguns teóricos da revolução ainda as saudaram como retorno do movimento operário, mas, logo se viu, elas eram bastante peculiares. Não se baseavam em classe, mas sobretudo em etnia (o movimento pelos direitos civis), gênero (o feminismo) e estilo de vida (o pacificismo e o ambienta- 
lismo), para ficar nos mais proeminentes. Tampouco visavam a revolução política, no sentido da tomada do poder de Estado. Não eram reações irracionais de indivíduos isolados, mas movimentação concatenada, solidária e ordeira de milhares de pessoas. Então não cabiam bem em nenhum dos dois grandes sistemas teóricos do século XX, o marxismo e o funcionalismo.

A ruptura está no próprio nome que o fenômeno ganhou. Tratava-se seguramente de "movimentos", no sentido de ações coordenadas de mesmo sentido acontecendo fora das instituições políticas, mas não eram, de modo algum, protagonizadas por mobs, tampouco por "proletários". Eram jovens, mulheres, estudantes, profissionais liberais, sobretudo de classe média, empunhando bandeiras em princípio também novas: não mais voltadas para as condições de vida, ou para a redistribuição de recursos, mas para a qualidade de vida, e para afirmação da diversidade de estilos de vivê-la. Essas demandas "pós-materiais", como as chamou Inglehart (1971), se completavam com a opção por formas diretas de ação política e pela demanda por mudanças paulatinas na sociabilidade e na cultura, a serem logradas pela persuasão, isto é, léguas longe da ideia de tomada do poder de Estado por revolução armada. Então eram, sim, movimentos, mas movimentos sociais.

Um novo fenômeno demandava nova explicação. Nos anos 1970, três famílias de teorias dos "movimentos sociais" se apresentaram.

McCarthy e Zald (1977) são os epígonos da Teoria de Mobilização de Recursos (TMR), que fizeram perante as explicações das mobilizações coletivas em termos de emoções coletivas, exacerbando o extremo oposto: sua racionalidade. Contra o funcionalismo, defenderam que, longe de expressão caótica de insatisfações individuais não canalizadas pelas instituições, movimentos, como o por direitos civis nos Estados Unidos, tinham sentido e organização. Contra 
as versões economicistas do marxismo, argumentaram que descontentamentos e motivos para a mobilização, sejam eles privações materiais ou interesses de classe, sempre existem, o que os tornariam inócuos para explicar a formação de mobilizações coletivas. Assim, mais importante que identificar as razões seria explicar o processo de mobilização.

Longe de emotiva, a decisão de agir seria ato de deliberação individual, resultado de cálculo racional entre benefícios e custos. Isto a TMR herdou de Olson. Mas a ação coletiva só se viabilizaria na presença de recursos materiais (financeiros e infraestrutura) e humanos (ativistas e apoiadores) e de organização, isto é, da coordenação entre indivíduos doutro modo avulsos. A criação de associações ou, mais comumente, o uso de estruturas comunitárias preexistentes, daria a base organizacional para os movimentos sociais.

A TMR aplicou a sociologia das organizações ao seu obje52 to, definindo os movimentos sociais por analogia com uma firma. A racionalização plena da atividade política fica clara no argumento da burocratização dos movimentos sociais, que, gradualmente, criariam normas, hierarquia interna e dividiriam o trabalho, especializando os membros, com os líderes como gerentes, administrando recursos e coordenando as ações (McCarthy e Zald, 1977). Quanto mais longevos, mais burocratizados os movimentos se tornariam.

A longevidade, por sua vez, dependeria da capacidade de os movimentos vencerem a concorrência. Isto é, vários movimentos podem se formar em torno de um mesmo tema, compondo uma "indústria de movimento social", na qual haverá cooperação, mas também competição, em torno de recursos materiais e de aderentes a serem garimpados num mercado de consumidores de bens políticos. Daí a emergência de conflitos internos que gerariam faccionalismo, com dissolução de movimentos grandes e formação de subunidades em torno de uma mesma causa. 
A TMR, portanto, avalia os movimentos sociais igualando-os a um fenômeno social como outro qualquer, dotado das mesmas características que os partidos políticos, por exemplo. A explicação privilegia a racionalidade e a organização e nega relevo a ideologias e valores na conformação das mobilizações coletivas.

A antipatia que gerou na esquerda, ao comparar movimentos com empresas, talvez explique a pequena ressonância da TMR na Europa e sua inexpressiva entrada na América Latina. Já em casa, teve impacto grande e imediato. Cerca de $56 \%$ dos artigos publicados nas principais revistas norte-americanas de sociologia e ciência política, nos anos 1970, usavam o approach (Mueller, 1992, p. 3).

As críticas recebidas também foram volumosas. Insurgindo-se contra teorias excessivamente culturalistas, a TMR foi parar no extremo oposto: inflou a faceta racional e estratégica da ação coletiva. À cultura restou lugar residual. Não há conceito para descrevê-la. Supõe-se a presença de crenças e processos cognitivos na formação da ação coletiva termos como "lealdades" e "consciência" o denotam -, mas não se sabe nada sobre seu modus operandi. Além do mais, pressupõe um ator individual, sem levar em conta o problema da formação de uma identidade coletiva (Piven e Cloward, 1995). Doutra parte, a teoria prima por uma análise conjuntural, sem vincular os movimentos a macroestruturas ou situá-los em processos de mais longo alcance.

O enquadramento macro-histórico do fenômeno aparece nas duas outras teorias sobre os movimentos sociais. A Teoria do Processo Político (TPP) e a Teoria dos Novos Movimentos Sociais (TNMS) nasceram dos debates sobre a revolução, ou melhor, da exaustão dos debates marxistas sobre as possibilidades da revolução. Ambas se insurgiram contra explicações deterministas e economicistas da ação coletiva e contra a ideia de um sujeito histórico universal. As duas constroem explicações macro-históricas que repelem 
a economia como chave explicativa e combinam política e cultura na explicação dos movimentos sociais. Contudo, a TPP investe numa teoria da mobilização política enquanto a TNMS se alicerça numa teoria da mudança cultural.

Embora constituída nos Estados Unidos, como a TMR, a TPP engloba casos europeus em suas análises. Charles Tilly (1975) estudou em profundidade o movimento revolucionário na França e os movimentos por reformas na Inglaterra, nos séculos XVIII e XIX. Já Sidney Tarrow (1993) se deteve no movimento de redemocratização da Itália da segunda metade do século XX e Doug McAdam no movimento pelos direitos civis nos Estados Unidos (1982) ${ }^{1}$. Tilly, o grande nome dessa linha, construiu uma sociologia política histórica, que combina tradições e cuja ambição é identificar os mecanismos que organizam os macroprocessos políticos no Ocidente, por meio da comparação entre casos. O elo entre esse projeto e o debate marxista está em 54 seu clássico From mobilization to revolution (1978). Rigorosamente, o título devia ser invertido, uma vez que Tilly sai do debate sobre revoluções, afinal episódios históricos raros, para estabelecer as bases da discussão sobre fenômeno mais abundante: as mobilizações coletivas.

Tilly critica a tradição sociológica por ter segregado o estudo das disputas entre elites da análise dos movimentos populares. Argumenta alternativamente que ambos são perfeitamente racionais e dotados da mesma lógica, pertencendo a uma única classe de fenômenos. A distinção entre eles é de grau de organização e de uso da violência, não de natureza. A prevalência de uma dessas formas depende de dois gêneros de parâmetros: um, político; outro, histórico-cultural.

O conceito de "estrutura de oportunidades políticas” (EOP) dá o parâmetro político. Tarrow (1998, p. 20)

\footnotetext{
${ }^{1}$ William Gamson também é frequentemente incluído nesta corrente, com seus Power and discontent (1968) e The strategy of social protest (1975).
} 
argumenta que, quando há mudanças nas EOPs, isto é, nas dimensões formais e informais do ambiente político, se abrem ou se criam novos canais para expressão de reivindicações para grupos sociais de fora da polity. Isso pode ocorrer pelo aumento de permeabilidade das instituições políticas e administrativas às reivindicações da sociedade civil, provocadas por crises na coalizão política no poder; por mudanças na interação política entre o Estado e a sociedade, especialmente a redução da repressão a protestos; e pela presença de aliados potenciais (Kriesi, 1995).

Em EOP favoráveis, grupos insatisfeitos organizamse para expressar suas reivindicações na arena pública ${ }^{2}$. Como a TMR, a TPP supõe que a coordenação dentre os potenciais ativistas é crucial para produzir um ator coletivo, mas os agentes coletivos não são preexistentes; eles se formam por contraste durante o próprio processo contencioso. A TPP adiciona um elemento cultural à explicação. A coordenação depende de solidariedade, produto de catnet, isto é, da combinação entre o pertencimento a uma categoria (catness) e a densidade das redes interpessoais vinculando os membros do grupo entre si (netness) (Tilly, 1978, p. 74).

Contudo, a solidariedade não gera ação, se não puder contar com "estruturas de mobilização": recursos formais, como organizações civis, e informais, como redes sociais, que favorecem a organização. A mobilização é, então, o processo pelo qual um grupo cria solidariedade e adquire controle coletivo sobre os recursos necessários para sua ação. Mas tudo isso, e essa é uma das diferenças em relação à TMR, só configura um movimento social diante de oportunidades políticas favoráveis. Enquanto a TMR enfatiza recursos materiais disponíveis para ativistas individuais, a

\footnotetext{
${ }^{2}$ Nas situações em que vários grupos se organizam sequencialmente, um ciclo de protestos se forma (Tarrow, 1983 p. 36).
} 
TPP prioriza uma estrutura de incentivos e/ou constrangimentos políticos, que delimita as possibilidades de escolha dos agentes entre cursos de ação.

Esta perspectiva afeta a compreensão das instituições políticas. A mobilização baseia-se num conflito entre partes, uma delas momentaneamente ocupando o Estado, enquanto a outra fala em nome da sociedade. Essas posições são variáveis, os atores migram entre elas. Por isso, a análise tem de suplantar as barreiras convencionais que definem "Estado" e "sociedade" como duas entidades coesas e monolíticas. Assim, em vez de definir a equação como movimentos sociais versus Estado, a TPP opõe "detentores do poder" (os membros da polity), que têm controle ou acesso ao governo que rege uma população (incluídos os meios de repressão), e "desafiantes", que visam obter influência sobre o governo e acesso aos recursos controlados pela polity. Um movimento social é definido, então, como uma "interação conten56 ciosa", que "envolve demandas mútuas entre desafiantes e detentores do poder”, em nome de uma população sob litígio (Tilly, 1993).

Estado nacional e movimentos sociais não são, então, atores, mas formas de ação coletiva. Formas para as quais Tilly provê uma explicação histórico-estrutural, vinculandoas a uma teoria da formação do Estado nacional. Os movimentos sociais seriam uma invenção Ocidental, o produto último de uma série de mudanças estruturais, que culminaram na centralização de poder político na Inglaterra do século XVIII ${ }^{3}$ : o fortalecimento do parlamento, vis-àvis poder local e coroa, nacionalizou as decisões políticas; a competição eleitoral pelos postos nacionais aumentou, fomentando a congregação de facções locais em um sistema partidário. Essa nacionalização da política enfraqueceu as

\footnotetext{
${ }^{3}$ Simplificadamente, o argumento, baseado no caso inglês, é que campanhas militares levaram à expansão do Estado, com burocratização e crescente intervenção na sociedade (por meio de taxação), o que causou o fortalecimento do parlamento.
} 
formas locais de expressar demandas e abriu oportunidades para o surgimento de ações "para-parlamentares", como petições e comícios, visando influenciar a tomada de decisões no parlamento.

Os movimentos sociais seriam, então, uma forma histórica de expressão de reivindicações, que não existiu sempre, nem em toda a parte. Aqui aparece a outra perna da explicação, a histórico-cultural, sintetizada no conceito de "repertório". Tilly (1978, pp. 150 e ss.) argumenta que é bastante exíguo o conjunto de formas de ação política disponíveis para os agentes em determinada sociedade. Na verdade, distingue apenas dois "repertórios de ações coletivas" no Ocidente ${ }^{4}$, um que antecede, outro que sucede a centralização do poder político.

Até o século XVIII, teríamos movimentos paroquiais, defensivos de direitos e recursos de grupos prejudicados com a paulatina centralização política. Giravam em torno de mesmos temas (alimentos, impostos, resistência ao alistamento militar) e tinham mesmo locus (mercados, igrejas, festivais), mas eram particulares, comunitários: sua forma variava de lugar, de ator e de situação. O repertório de ação coletiva seria, então, "bifurcado", envolvendo ação direta, com farto uso de violência, no plano local, mas operando por representação quando questões nacionais estavam envolvidas (Tilly, 1978, p. 271). Tendo já analisado um século de episódios de mobilização na Inglaterra, França e Alemanha, por meio de notícias de jornal, Tilly et al. (1975) apresenta 1830 como momento de inflexão. Desde aí se pode falar de movimentos nacionais e autônomos, que prescindem de mediações entre demandantes e autoridades. Baseados em novas solidariedades, compondo associações e sindicatos,

\footnotetext{
4 "Em um dado momento do tempo, o repertório de ações coletivas disponível para uma população é surpreendentemente limitado. Surpreendente, dados os meios inumeráveis pelos quais as pessoas podem, em princípio, desdobrar seus recursos ao perseguirem fins, finalidades comuns" (Tilly, 1978, p. 151).
} 
eles seriam menos violentos, mas mais ofensivos, clamando pela expansão de direitos e por maior acesso a recursos. Os temas também teriam mudado (eleições, comportamento do governo, economia, trabalho, impostos, escravidão), assim como os locais em que ocorriam (pubs, cafés - nas cidades). O repertório seria desde então "modular": as mesmas formas (comícios, greves, assembleias, passeatas) servindo a diferentes tipos de atores, lugares e temas.

Repertório é, pois, um conceito referido a um longo período de tempo e a um conjunto relativamente amplo de atores em litígio, o que é ressaltado pela adição de of contention $^{5}$. Tilly apoiou-se numa perspectiva pragmática, definindo repertório como "um conjunto limitado de rotinas que são aprendidas, compartilhadas e postas em ação por meio de um processo relativamente deliberado de escolha" (Tilly, 1995 , p. 26). Os agentes, em meio ao processo de luta, escolheriam dentre as maneiras convencionalizadas de interação 58 presentes no repertório aquelas mais adequadas à expressão de seus propósitos. Isto é, os agentes atribuíram o sentido às formas, que pode ser tanto de contestação quanto de reiteração da ordem. É o caráter vazado, sem semântica, do repertório que permite sua partilha entre atores opostos. Isto é, o repertório de ação coletiva não é peculiar a um grupo, mas a uma estrutura de conflito.

A TPP abre, portanto, mais espaço para a cultura na explicação da ação coletiva do que a TMR - pero no mucho. O conceito de repertório descreve bem características culturais de longa duração, mas serve pouco para lidar com variações no interior de uma mesma conjuntura. Já "solidariedade" e catnet têm peso explicativo bem reduzido e não competem na armação da teoria com os outros dois conceitos carros-chefe, EOP e repertório.

\footnotetext{
5 “[...] repertórios de contenção [of contention] são os meios estabelecidos por meio dos quais pares de atores fazem e recebem reivindicações relativas aos interesses uns dos outros" (Tilly, 1993, pp. 264-265).
} 
Nos Estados Unidos, a TPP teve de inicialmente competir com a TMR, mas logo a suplantou. Lá, como na Europa, a teoria encontrou legião de adeptos, que a aplicaram a inúmeros países e períodos. Na América Latina seu sucesso foi bem mais modesto. No Brasil, o trabalho pioneiro nessa direção é o de Boschi (1987), que utiliza uma versão estilizada da TPP para tratar das mobilizações durante o processo de redemocratização.

Embora não constituam uma escola coesa, como a TPP e a TMR, há um ar de família dentre os principais teóricos dos Novos Movimentos Sociais: Alain Touraine, Jürgen Habermas, Alberto Melucci ${ }^{6}$. São todos críticos da ortodoxia marxista, mas mantêm o enquadramento macro-histórico e a associação entre mudança social e formas de conflitos. Nisso não diferem da TPP. A especificidade está em produzir uma interpretação efetivamente cultural para os MS.

Embora cada qual tenha sua própria teoria da modernidade, compartilham mais ou menos o mesmo argumento central. Ao longo do século XX, uma mudança macroestrutural teria alterado a natureza do capitalismo, cujo centro teria deixado de ser a produção industrial e o trabalho. Uma nova sociedade se vislumbraria, dando lugar também a novos temas e agentes para as mobilizações coletivas.

Em La voix et le regard (1978) e, com mais precisão, em $O$ retorno do ator (1983), Alain Touraine distingue dois padrões de sociedade, aos quais corresponderiam dois tipos de movimento. A sociedade industrial teria por fulcro a indústria e o trabalho industrial e nela vigeria a divisão entre o plano da produção, regido pela técnica, e o da reprodução, o reino da cultura. Os conflitos produtivos predominariam e os atores das mobilizações seriam os trabalhadores industriais. Isto é, o movimento operário teria sido a forma típica de

\footnotetext{
${ }^{6}$ Apresentações mais detidas da TNMS podem ser encontradas em Pichardo (1997), Hannigan (1985), Alexander (1998), entre outros.
} 
conflito da sociedade industrial, correspondente ao processo de industrialização europeia.

Após os anos 1960 teria se configurado um novo padrão de sociedade, que Touraine, inicialmente, chama de "sociedade programada" e depois de "sociedade pós-industrial", na qual a indústria e o trabalho teriam perdido centralidade. Os conflitos do trabalho teriam se diluído, processados pelas instituições democráticas, como expansão de direitos, e pelas instituições capitalistas, como aumento de salários. A dominação teria se tornado eminentemente cultural, feita por meio do controle da informação por uma tecnocracia. Técnica e cultura passariam a interpenetrar-se, as distinções entre mundo público e privado teriam se nublado, fazendo com que os conflitos, antes restritos ao plano econômico, avançassem para a vida privada (família, educação, sexo) e ganhassem dimensões simbólicas:

"o conflito não está mais associado a um setor considerado fundamental da atividade social, à infraestrutura da sociedade, ao trabalho em particular; ele está em toda a parte" (Touraine, 1989b, p.13).

As novas mobilizações não teriam uma base social demarcada. Seus atores não se definiriam mais por uma atividade, o trabalho, mas por formas de vida. Os "novos sujeitos" não seriam, então, classes, mas grupos marginais em relação aos padrões de normalidade sociocultural. Isto é, poderiam vir de todas as minorias excluídas (Touraine lista negros, hispânicos, índios, homossexuais, mulheres, jovens, velhos, intelectuais) e teriam em comum uma atitude de oposição. Seus exemplos principais são os movimentos feminista e ambientalista.

Esses "novos movimentos sociais" não se organizariam em combate ao Estado, nem com a finalidade de conquistá-lo. Recorrendo a formas de ação direta, "no nível dos 
próprios problemas sociais", seriam agentes de pressão social, voltados para persuadir a sociedade civil. Aí está a grande contribuição de Touraine para esse debate (veja-se em Cohen, 1985): retomar o conceito até então um tanto esquecido de "sociedade civil", como reino apartado do Estado e do mercado, e no qual a inovação social poderia se configurar. Os movimentos sociais nasceriam na sociedade civil e, portadores de uma nova "imagem da sociedade", tentariam mudar suas orientações valorativas. Os movimentos sociais aparecem, então, como o novo ator coletivo, portador de um projeto cultural. Em vez de demandar democratização política ao Estado, demandariam uma democratização social, a ser construída não no plano das leis, mas dos costumes; uma mudança cultural de longa duração gerida e sediada no âmbito da sociedade civil.

Jürgen Habermas argumenta em direção similar, associando um novo padrão de mobilização coletiva ao capitalismo tardio. O conflito capital-trabalho, típico do século XIX, teria sido mediado e desinflado pelo Estado. O custo teria sido uma hipertrofia do Estado, que cresceu para atender às suas novas tarefas de regulador da produção e do mercado, ao passo que a efetivação das políticas sociais requisitou a expansão da burocracia e da normatização jurídico-administrativa da vida privada - da família, da educação, da vida individual (Habermas, 1984). Esses processos teriam alimentado a expansão da lógica sistêmica, típica da economia e da política institucional, para o mundo cultural, gerando duas tendências que se reforçam mutuamente: a expansão da monetarização, própria ao subsistema econômico, para todas as relações sociais, e a burocratização, própria ao subsistema político, que minaria as formas tradicionais de interação. A expansão da racionalidade instrumental, de mecanismos e procedimentos típicos da esfera sistêmica, para os espaços destinados à interação e à comunicação intersubjetiva, geraria um "empobrecimento cultural”, uma "colonização do mundo da vida". 
De outra parte, o mundo do trabalho teria perdido centralidade no capitalismo tardio, esvaindo a utopia oitocentista de "autogoverno dos trabalhadores", que inspirou a formação do movimento operário. Daí o deslocamento das "energias utópicas" para uma "nova zona de conflito", aquela afetada pelo processo de colonização do mundo da vida (Habermas, 1987). Aí se configurariam "novos movimentos sociais", não mais motivados por questões redistributivas, mas empenhados numa luta simbólica em torno de definições da boa vida. Os novos movimentos sociais seriam, então, formas de resistência à colonização do mundo da vida, reações à padronização e à racionalização das interações sociais e em favor da manutenção ou expansão de estruturas comunicativas, demandando qualidade de vida, equidade, realização pessoal, participação, direitos humanos (Habermas, 1981, p. 33).

Os novos movimentos sociais seriam "subculturas defen62 sivas", nascidas em reação a "situações-problema". Sua base social seriam grupos cujo estilo de vida teria sido afetado por dois grandes tipos de gêneros. De uma parte, formarse-iam em torno dos green problems, isto é, dos efeitos colaterais do desenvolvimento capitalista: poluição, urbanização, experiências com animais para produção de remédio etc. De outra parte, seriam reações a problemas da over-complexity da sociedade contemporânea: riscos potenciais de usinas nucleares, poder militar, manipulação genética, controle e uso de informações pessoais, isto é, problemas que geram "riscos invisíveis" (Habermas, 1981).

Habermas, contudo, distingue dois tipos. Os "movimentos de liberação", de caráter emancipatório, demandantes da universalização de direitos, na tradição burguesa-socialista, teriam ainda caráter ofensivo, caso do movimento pelos direitos civis e do feminismo. Já os movimentos "defensivos" se bifurcariam em dois subtipos. Os tradicionais, de defesa da propriedade, teriam por base social a velha classe média, 
ameaçada pelo dinamismo contemporâneo. Seriam movimentos de vizinhança; de pais de alunos; contra impostos. Os genuinamente "novos" movimentos sociais seriam os insurgentes contra a colonização do mundo da vida, contra os papéis institucionalizados de consumidor da sociedade de mercado, de cliente dos serviços públicos do Welfare State, e mesmo de cidadão, fazendo a crítica das instituições políticas. Seriam propositores de novas formas de cooperação e de comunidade. Os exemplos: o movimento de jovens, o alternativo, o ambientalista e o pacifista. Em 1985, Habermas realocou o feminismo dentre os novos movimentos sociais, já que também demandaria a transformação das formas de vida.

Os novos movimentos sociais defenderiam formas autogestionárias, novos modelos participatórios e a criação de "contrainstituições", protegidas da influência dos partidos de massa, da indústria cultural e da mídia, nas quais a comunicação livre fosse possível. Fariam, então, uma "política expressiva”, desvinculada de qualquer demanda por bens ou cargos políticos, e voltada para a afirmação de identidades e para a preservação da autonomia e de formas de vida sob ameaça da racionalização sistêmica levada a cabo pelo Estado e pelo mercado.

Melucci (1980) parte de teses similares às de Touraine e Habermas sobre a sociedade contemporânea, caracterizando-a como pós-industrial, complexa e com uma interpenetração entre mundo público e privado. Na sociedade industrial, o mecanismo de acumulação e de controle social residiria na exploração da força de trabalho. Já na sociedade "avançada" ou "de massas" - ou "sociedade da informação” (Melucci, 1996) -, se configuraria um novo padrão de dominação, baseado na produção e controle de informação e na intervenção nas relações sociais, e exercido por meio da ciência e da tecnocracia. A distinção entre as esferas pública e privada teria se extinguido, transformando as relações interpessoais (consumo, lazer, relação com a nature- 
za), sexuais e a identidade biológica (nascimento, morte, doença, envelhecimento) em novas zonas de conflito. Isto é, o conflito teria se deslocado do mundo do trabalho em direção a duas tópicas principais. A primeira delas é o corpo, que, na sociedade avançada, se tornou objeto científico, medicalizado; objeto da moda e do consumo, padronizado. Em reação, emergiriam movimentos redefinindo-o como parte da natureza; sede de desejos; nexo das relações interpessoais. Os exemplos são os movimentos de mulheres, gays, jovens, o ambientalista e o de contracultura (Melucci, 1989). A outra tópica é a da "utopia regressiva com forte componente religioso" (Melucci, 1980). Seriam formas religiosas, orientadas por um "mito global de renascimento", de defesa contra um mundo racionalizado, exprimindo desejos de integração e negando hierarquias e diferenças da sociedade avançada. Os exemplos são vários tipos de "integralismo": comunitário, político-religioso, místico-ascético ${ }^{7}$.

64 Os novos movimentos sociais seriam, então, formas particularistas de resistência, reativas aos rumos do desenvolvimento socioeconômico e em busca da reapropriação de tempo, espaço e relações cotidianas. Contestações "pós-materialistas", com motivações de ordem simbólica e voltadas para a construção ou o reconhecimento de identidades coletivas.

Embora Habermas e Touraine tivessem já falado dos novos movimentos sociais como portadores de identidades sociais também novas, foi Melucci quem se dedicou a produzir uma teoria da identidade coletiva. Atento aos mecanismos micro e mesossociológicos que vinculariam o novo padrão de sociedade, as experiências individuais da comple-

\footnotetext{
${ }^{7}$ Para Melucci, os membros dos NMS seriam os grupos afetados pela manipulação do desenvolvimento socioeconômico e, portanto, podendo envolver tanto os marginalizados quanto os integrados na estrutura social. Melucci, portanto, inclui diferencial e hierarquicamente estratos sociais, sem apresentar uma base homogênea para esses estratos. Mas a nova classe média, por ter lugar central em redes e ser altamente dotada de recursos cognitivos e relacionais, seria a iniciadora natural das mobilizações.
} 
xificação e as novas formas de ação política, Melucci construiu uma nova teoria psicossocial da ação coletiva.

Melucci (1988) criticou tanto as explicações psicológicas para a formação da ação coletiva, em termos de irracionalidade das massas, quanto as macroexplicações, nas quais condições sociais comuns determinam o comportamento dos atores. Num caso haveria "ação sem atores", noutro, "atores sem ação". Em ambos, faltariam mediações entre comportamentos individuais e o fenômeno coletivo "movimento". Assim se elidiria o problema principal, que Melucci põe na agenda: Como um ator coletivo é formado ou quais relações e processos levam os indivíduos a se envolverem coletivamente numa ação política?

Para respondê-la, Melucci recorre a uma argumentação construcionista e processual. Os atores construiriam a ação coletiva, à medida que se comunicam, produzem e negociam significados, avaliam e reconhecem o que têm em comum, tomam decisões. Assim:

"A identidade coletiva é uma definição interativa e compartilhada produzida por numerosos indivíduos e relativa às orientações da ação e ao campo de oportunidades e constrangimentos no qual a ação acontece" (Melucci, 1988, p. 342).

Como a TPP, portanto, Melucci admite que há oportunidades e constrangimentos objetivos à ação coletiva, mas eles são mediados pelas percepções dos agentes, por uma apreensão cognitiva das possibilidades e limites, produzida no próprio curso da ação:

“Indivíduos agindo coletivamente ‘constroem' suas ações por meio de investimentos 'organizados'; isto é, eles definem em termos cognitivos o campo de possibilidades e limites que percebem, enquanto, ao mesmo tempo, ativam 
suas relações de modo a dar sentido ao seu 'estar junto' e aos fins que perseguem” (Melucci, 1988, p. 332).

Esse senso de "nós" depende da permanente negociação e redefinição de orientações comuns acerca dos fins, dos meios e do ambiente da ação. Liderança e organização surgiriam como formas de manter estáveis essas orientações.

Como Tilly - e à diferença de Touraine e Habermas -, Melucci define os movimentos sociais não como um agente, mas como uma forma de ação coletiva, que surge a partir de um campo de oportunidades e constrangimentos e que possui organização, lideranças e estratégias. Melucci incorpora também a tese da TMR e da TPP de que relações ou organizações já existentes facilitam o engajamento. Mas em vez de falar de "estruturas de mobilização", recorre à noção mais compatível com a agency que quer enfatizar: as "redes de relacionamento" (Melucci, 1988, p. $66340)$. Nelas se construiriam a motivação para a ação coletiva e a própria interação.

Mas, à diferença da TPP, parte substancial da atividade dos movimentos consistiria no processo de construção de uma identidade coletiva, que é um fim em si mesmo; daí a ideia de que os NMS seriam "expressivos". Sendo negociada, a identidade coletiva não se consubstancia, ela é um processo, sujeita continuamente à redefinição, conforme as negociações entre os agentes. Ela envolve uma operação racional, mas a decisão do engajamento não se limita a um cálculo custo/benefício, é também produto de um "reconhecimento emocional”.

Essa teoria procura, então, incluir três dimensões da ação coletiva. A identidade coletiva seria produzida a partir da definição de um "framework cognitivo" acerca dos fins, meios e campo da ação; da ativação prática de relações entre atores (interação, comunicação, influência, negociação, tomada de decisão); e do investimento emocional que os 
leva a se reconhecerem como membros de um grupo. Com Melucci, as emoções retornam à análise da ação coletiva. Mas com sinal invertido: não para explicar a desmobilização, mas como motivação para o engajamento. Temos aqui uma genuína teoria cultural para a formação dos movimentos sociais, que explica a conversão de cidadãos comuns em ativistas por meio de um processo que envolve simultaneamente racionalidade e emoção.

Touraine, Habermas e Melucci têm teorias particulares, mas confluem para o mesmo postulado central, o da especificidade dos movimentos sociais da segunda metade do século XX. Para todos, uma mudança macrossocial teria gerado uma nova forma de dominação, eminentemente cultural (por meio da tecnologia e da ciência) e borrado as distinções entre público e privado, acarretando mudanças nas subjetividades e uma nova zona de conflito. As reivindicações teriam se deslocado dos itens redistributivos, do mundo do trabalho, para a vida cotidiana, demandando a democratização de suas estruturas e afirmando novas identidades e valores. Estaria em curso uma politização da vida privada. Os movimentos de classe dariam lugar, assim, a novos movimentos expressivos, simbólicos, identitários, caso do feminismo, do pacifismo, do ambientalismo, do movimento estudantil. Isto é, os movimentos mais em evidência no momento em que escreviam.

Os novos movimentos sociais seriam, então, antes grupos ou minorias que grandes coletivos. Suas demandas seriam simbólicas, girando em torno do reconhecimento de identidades ou de estilos de vida. Recorreriam à ação direta, pacífica, baseada numa organização fluída, não hierárquica, descentralizada, desburocratizada. Não se dirigiriam prioritariamente ao Estado, mas à sociedade civil, almejando mudanças culturais no longo prazo. Esses analistas, portanto, entendem que a ênfase cultural é uma característica distintiva das novas mobilizações, razão 
pela qual usaram o advérbio "novo" para distingui-los dos "velhos". A sobrevalorização da cultura na análise dever-seia, então, a um imperativo do objeto, não a uma escolha do analista.

Avulsas ou em combinações, as TNMS fizeram carreira na América Latina. Foram de longe a perspectiva mais aplicada para a explicação de casos nacionais, durante as décadas de 1980 e 1990, como mostram várias revisões bibliográficas desse campo (Haber, 1996; Davis, 1999; Shefner, 2004), e orientaram a agenda para a produção de estudos de casos, concentrados no processo de construção de identidades coletivas ${ }^{8}$. Contudo, houve uma transição de autores de referência. A hegemonia foi primeiro de Touraine, único dentre esses autores a ter refletido diretamente sobre a América Latina - como em Palavra e sangue (1989). A transposição do esquema apresenta problemas. Touraine reconhece que as demandas econômicas seguem 68 relevantes na América Latina; no entanto, para englobar seus movimentos dentre os "novos", argumenta que haveria aqui uma combinação sui generis de demandas materiais e pós-materiais (Touraine, 1989b). Ao entrar em diálogo direto com o caso - e com analistas brasileiros - , Touraine ganhou enorme notoriedade no Brasil da redemocratização. Em doses variadas, sua teoria foi aplicada para explicar o surgimento de "novos atores" e "novos movimentos sociais" nas periferias dos grandes centros urbanos ao longo dos anos 1980 - caso, por exemplo, de Sader (1988). No começo dos anos 1990, Touraine perdeu o trono para Habermas, que, mais para o fim da década de 1990, cedeu espaço para Melucci, como se vê pela concentração das investigações em torno do tema da identidade coletiva. Em conjunto, a TNMS orientou a predileção latino-ame-

\footnotetext{
${ }^{8}$ Para balanços da literatura brasileira desta hora, veja-se Cardoso (1987) e Kowarick (1987).
} 
ricana pelo estudo da cultura política "inovadora”, como mostra Roberts (1997), e pela construção de identidades, significados e discursos, do que são exemplares os estudos compilados por Alvarez e Escobar (1992). O forte influxo dessa teoria deu aos estudos de movimentos sociais dentre nós um acento marcadamente culturalista.

Em suma, as três teorias - agora clássicas - sobre movimentos sociais têm contornos bastante peculiares. A TMR focalizou a dimensão micro-organizacional e estratégica da ação coletiva e praticamente limou o simbolismo na explicação. Já a TPP privilegiou o ambiente macropolítico e incorporou a cultura na análise por meio do conceito de repertório, embora não tenha lhe dado lugar de honra. A TNMS, inversamente, acentuou aspectos simbólicos e cognitivos - e mesmo emoções coletivas -, incluindo-os na própria definição de movimentos sociais. Em contrapartida, deu menor relevo ao ambiente político em que a mobilização transcorre e aos interesses e recursos materiais que ela envolve.

\section{Polêmica e conciliação}

A exposição das três grandes teorias dos movimentos sociais e a explicitação de seus pressupostos e limites ocuparam o debate até o começo dos anos $1980^{9}$. Logo em seguida, brigaram bem, no que se convencionou chamar a polêmica identidade versus estratégia. Muitas críticas foram feitas de parte a parte, mas dois autores, Craig Calhoun e Jean Cohen, são emblemáticos do espírito do debate.

Calhoun (1995) escreveu artigo capciosamente intitulado "Novos movimentos sociais do começo do século XIX". Aí argumenta que as características que a TNMS considera novas e peculiares a movimentos do século XX já esta-

\footnotetext{
${ }_{9}^{9}$ Do que é expressivo o número especial da Social Research (vol. 52, n 4), organizado por Jean Cohen, em 1985, e no qual Tilly, Touraine e Melucci - acompanhados por Claus Offe e Klaus Eder - apresentaram suas interpretações sobre movimentos sociais.
} 
vam em seus similares do XIX: multidimensionalidade; demandas não materiais; criação de identidades. A ênfase economicista anterior é que teria impedido os analistas de atentarem para a diversidade de atores (de diferentes extrações sociais e dos dois gêneros), e para aspectos culturais e simbólicos bastante salientes, sobretudo em movimentos religiosos e de temperança. Assim, a tese da novidade de agenda das mobilizações nas sociedades pós-industriais, mais culturais que econômicas, expressaria mais os óculos dos analistas que as motivações dos agentes.

Vários autores (por exemplo, Plotke, 1990) seguiram nessa trilha, atacando a distinção entre "novos" e "velhos" movimentos, argumentando que, em qualquer tempo, movimentos sociais combinam demandas materiais e simbólicas. Também denunciaram a visão idealizada do objeto, que teria levado a TNMS a buscar nos movimentos sociais um novo sujeito revolucionário, com a luta transposta do plano da eco70 nomia para o da cultura; e mesmo a encampar acriticamente suas teses e categorizações, sobretudo o adjetivo "novo".

A TNMS foi acusada ainda de se restringir ao plano societário, negligenciando a relação dos movimentos sociais com a dinâmica político-institucional. Seu conceito de identidade foi apontado como vago, por ora parecer se referir a uma identidade social concreta, ora a uma ideia filosófica; ora nomear identidades individuais, ora de grupos (Pichardo, 1997). A TNMS teria também demonstração empírica limitada ou insuficiente e explicaria mal casos não europeus, como os latino-americanos, em que as mudanças estruturais de que falam não aconteceram ou seguiram outros padrões; e por negligenciar mobilizações à direita e em torno de demandas religiosas e comunitárias (Edelman, 2001).

O segundo artigo marcante nessa polêmica é de Jean Cohen (1985), que acoplou TMR e TPP num único pacote, o "paradigma da mobilização de recursos", e o contrapôs ao 
“paradigma orientado para a identidade”, criando distinção polêmica, mas de sucesso na literatura. Na primeira caixinha ficariam os norte-americanos, a TMR e a TPP, “objetivistas", de "ênfase utilitarista" e cuja explicação focalizaria interesses, condições materiais e o caráter estratégico da ação coletiva. Em contraponto, a outra linhagem, europeia, seria "subjetivista" e atenta para intencionalidade, valores e identidades dos agentes mobilizados ${ }^{10}$.

Cohen (1985, pp. 678-679) simpatiza com o segundo bloco e critica o primeiro, por inábil em lidar com subjetividades e valores envolvidos nas mobilizações e, em consequência, em explicar a constituição de solidariedades e de identidades coletivas. Aponta também o excessivo estruturalismo e o determinismo político da TPP, patente na prevalência da "sociedade política" sobre a "sociedade civil" na análise. Cohen (1985, p. 682) tentava assim estabelecer o estatuto teórico desse último conceito, acusando os teóricos do Processo Político de incapacidade de distinguir entre sociedade civil e sociedade em geral.

Outra crítica frequente à TPP é ao conceito central de estrutura de oportunidades políticas, tido por demais abrangente e, por decorrência, pouco explicativo (Polletta, 1999). E, a despeito de seu declarado anti-durkheimianismo, Tilly é acusado de parentesco com o inimigo, por tomar a cultura como representações compartilhadas e atentar pouco para o caráter dinâmico e para a agency envolvida nos processos simbólicos (Piven e Cloward, 1995, p. 145).

Depois da guerra, o armistício. Pelo lado da TNMS, Melucci (1996) concedeu que as teorias adversárias eram hábeis em lidar com a racionalidade e a lógica da ação dos movimentos sociais, assimilando recursos, estratégias e oportunidades ao seu esquema. De seu lado, a TPP admi-

\footnotetext{
${ }^{10}$ A distinção, em parte construída a partir de ênfases analíticas, em parte numa distinção geográfica, também se difundiu entre nós, por exemplo, Gohn, 1997. Veja-se também Toni, 2001.
} 
tiu suas insuficiências na abordagem da cultura (Tilly, Tarrow, McAdam, 2001) e adotou o conceito - da TNMS - de "identidade coletiva", dando a ele uma definição relacional, como resultante de processos contínuos de "formação de fronteiras" entre grupos sociais e de ativação seletiva de pertencimentos sociais anteriores ${ }^{11}$. Kurzman (1997) deu versão algo construcionista ao conceito central, argumentando que uma estrutura de oportunidades nunca é a mesma para todos, pois os agentes a percebem e interpretam diferencialmente. Já a TMR perdeu força e adeptos ao longo do debate. Zald (1992, p. 335) reconheceu que ela explicava mal as microfundações da mobilização. Num esforço coletivo (McAdam, McCarthy e Zald, 1996), autores nessa perspectiva adotaram categorias da TPP e deram passos em direção à TNMS, buscando incorporar mais centralmente a cultura. Mueller (1992, p. 10) propôs um conceito adicional, o de "contextos de micromobilização", para descrever as intera-

72 ções face a face nas quais emergiriam os sentidos usados na interpretação das estruturas de oportunidades, na construção de reivindicações, lealdades e identidades coletivas.

Uma convergência mínima entre os enfoques "objetivista" e "subjetivista" se estabeleceu em torno da tese de que movimentos sociais não surgem pela simples presença de desigualdade, nem resultam diretamente de cálculos de interesses ou de valores. As mobilizações envolvem tanto a ação estratégica, crucial para o controle sobre bens e recursos que sustentam a ação coletiva, quanto a formação de solidariedades e identidades coletivas.

\footnotetext{
${ }^{11} \mathrm{Na}$ verdade, distinguem entre dois tipos de identidade: as embedded orientariam a vida cotidiana, e seriam múltiplas, uma vez que todo indivíduo pertence a múltiplas categorias sociais. Já as identidades detached, referidas "apenas a um domínio estreito, especializado de relações sociais intermitentes” (Tilly et al., 2001, p. 135), seriam produzidas pela hipérbole de uma das facetas embedded, no curso de um conflito específico e em relação a um interlocutor e a uma estrutura de oportunidades políticas. Seria essa identidade contextual a que orientaria mobilizações políticas.
} 
Daí se seguiram mútuas apropriações conceituais e várias novas definições do fenômeno ao longo dos anos 1990. Na esteira das sociologias relacionais, as teorias dos movimentos sociais desviaram a atenção dos processos e estruturas macro, causadores da mobilização, para o nível mesossociológico, de constituição de teias de interdependência social que lhe dão forma. Em vez de pensado por analogia a uma forma institucional - as "organizações não governamentais" - o ativismo passou a ser visto como fluxo contínuo de interação social. Donde a adoção generalizada da noção de redes sociais para descrevê-lo (Diani, 2003). Movimentos sociais seriam uma estruturação policêntrica, frouxa, de contornos ambíguos, englobando conexões formais e informais entre ativistas e organizações, pelas quais circulariam recursos, valores, informação, poder.

Expressivo dessa dupla conciliação, teórica e metodológica, que ambiciona abarcar dimensões estratégicas e simbólicas da ação coletiva, a formação de identidades coletivas e os incentivos e constrangimentos sociopoliticos à mobilização, sua estruturação e seu caráter fluído, é o conceito proposto por Mario Diani, que define movimentos sociais como:

"[...] redes de interações informais entre uma pluralidade de indivíduos, grupos e/ou organizações, engajadas em conflitos políticos ou culturais, com base em identidades coletivas compartilhadas" (1992, p. 1).

A partir dos anos 1990, as teorias dos movimentos sociais investiram, pois, em sínteses conceituais e abordagens integradas, ambicionando conjugar o estudo das práticas de mobilização e dos códigos culturais que as orientam e focalizando experiências peculiares de produção de sentidos e de identidades coletivas. Assim, nos termos de Giugni (1998, p. 365), o pêndulo explicativo que, nos anos 1980, ainda repousava sobre a estrutura, deslocou-se de vez para a cultura. 


\section{Reelaborações teóricas}

Depois da bonança teórica, veio o rebote empírico. A virada para o século XXI trouxe problemas novos. Houve uma mudança de escala do ativismo, de nacional a global. Os protestos contemporâneos envolvem ativistas e temas que atravessam fronteiras e se dirigem, muitas vezes, a instituições multilaterais ou a uma opinião pública transnacional. O Estado nacional deixa, assim, de ser o antagonista prioritário, desafiando todas as teorias dos movimentos sociais, que definiam o fenômeno em escala nacional. Além disso, o ativismo se profissionalizou. Em vários países do Ocidente, movimentos sociais se burocratizaram, se converteram em partido, se empresariaram ou assumiram a prestação de serviços estatais (Rootes, 2003). Assim se esmaeceu a auréola de inovação política que traziam desde os anos 1970. A associação entre novos movimentos e pautas "pós-materiais" também se esgarçou com a leva de mobilizações étnicas,

74 religiosas, comunitárias e conservadoras. Nelas, a cultura, sobretudo a questão da identidade, ganhou saliência, mas amalgamada a outras pautas, dando aos movimentos uma feição multi-issue (Tarrow, 2005). Por fim, o 11 de setembro fechou a era do protesto pacífico, abrindo a temporada das mobilizações policêntricas e violentas, com o terrorismo se candidatando à forma rotineira de mobilização coletiva do novo século.

Essas transformações obrigaram a remodelagem das teorias dos movimentos sociais, sobretudo de modo que lhes desse capacidade de explicar mais persuasivamente o caráter simbólico e a dimensão global do ativismo contemporâneo.

A TNMS sofreu mudanças de monta para tratar da globalização. As teses de Melucci (1996) sobre a "sociedade da informação" facilitaram a expansão da teoria do âmbito do Estado nacional para abranger uma sociedade global. A mobilização agora visaria não mais o Estado, mas a produção e circulação de conhecimento, tendo por bandeira 
sua democratização. Nessa linha, Castells (1996) argumenta que, na "sociedade de rede", as identidades coletivas e a própria globalização se tornariam os principais focos de mobilização, levada a cabo por meio de redes de comunicação baseadas na mídia e em novas tecnologias.

De outro lado, a TNMS foi se convertendo paulatinamente de teoria dos movimentos sociais em teoria da sociedade civil. As críticas recebidas mais as evidências empíricas de burocratização do ativismo aprofundaram a crise da distinção entre novos e velhos movimentos. A TNMS deixou, então, de associar a inovação a um ator, os movimentos, para atrelá-la a um locus, a sociedade civil. Definida em larga medida em negativo - a sociedade civil não é nem Estado, nem mercado, nem a esfera privada/íntima -, dela nasceriam demandas por autonomia não referidas nem ao poder político-institucional, nem a benefícios materiais, nem ao autointeresse. A conjunção entre a teoria do espaço público, que já estava em Habermas, com a de sociedade civil, recuperada por Touraine, foi cristalizada no livro de Cohen e Arato (1992), que virou referência na década de 1990. Esse novo espaço tornou-se o tema precípuo dos herdeiros da TNMS, que se deslocaram massivamente do estudo de movimentos sociais específicos para o das arenas públicas, nas quais se debatem as definições da boa vida. Daí a profusão de trabalhos empíricos não mais sobre o ativismo, mas sobre participação social, democracia deliberativa e seus correlatos.

A expansão do approach da sociedade civil para o ativismo transnacional foi automática. Fala-se de uma globalizing civil society, inovadora em temas e formas de ação (por exemplo, Clark, 2003). Essa visão positiva incide particularmente sobre a globalization-from-below, oriunda do Sul, em desafio à globalization-from-above, carreada por empresas e estados do Norte (Falk, 1999).

Já a TPP refinou-se para abranger o terrorismo - facilmente, pois a violência já estava no coração da teoria -, 
a burocratização e a globalização do ativismo e dar mais peso à cultura. Tilly, Tarrow e McAdam (2001) redefiniram mesmo o fenômeno sob estudo: movimentos sociais pertenceriam a um gradiente de formas de ação "contenciosa", donde se incluem partidos, nacionalismo, guerrilhas, terrorismo, guerras civis, revoluções. Os atores elegeriam dentre formas mais ou menos violentas, menos ou mais organizadas, conforme sua apreensão das estruturas de oportunidades. Esse contentious politics approach tem por agenda a busca de mecanismos comuns ${ }^{12}$ que, em diferentes sequências e combinações, estruturariam toda a variedade de episódios contenciosos. A teoria se torna eminentemente comparativa, e os movimentos sociais viram apenas uma das formas de ação investigadas. McAdam (1999) adaptou sua pesquisa sobre o movimento dos direitos civis a esse approach e Tarrow (2005) o aggiornou para tratar da transnacionalização do ativismo.

Assim, essas redefinições ampliaram o espectro empí76 rico recoberto pelas teorias, encampando conflitos políticos em geral (a contentious politics) e espaços políticos não institucionalizados (a teoria da sociedade civil), em arenas nacionais e globais.

Esse debate não encaminhou nova síntese; antes, atualizou a celeuma antiga. Os teóricos da sociedade civil global acusam a contentious politics de simplesmente transpor velhas categorias para nova escala, mantendo o sobrepeso das facetas materiais e organizacionais do ativismo e a subestimação da cultura. E seus mecanismos explicativos seriam tão numerosos, e com tantas combinações possíveis, que a explicação redundaria particular.

De seu lado, a contentious politics segue criticando a teoria da sociedade civil por subdimensionar interesses e organização e por recorrer a um conceito - o de socieda-

\footnotetext{
${ }^{12}$ A saber: atribuição de oportunidade e ameaça, apropriação social, brokerage, formação de categorias e de identidades; mudança de objeto; certificação; difusão; mudança de escala; radicalização e convergência.
} 
de civil global - vago e que superestima a estabilidade das articulações entre ativistas (Tarrow, 2005). O viés normativo igualmente permaneceria, com a predileção pelo estudo de movimentos "emancipatórios" e a negligência do terrorismo e das hierarquias entre as sociedades civis do norte e do sul presentes nas coalizões globais (Keane, 2003).

Em seu novo formato, as teorias ressoam diferencialmente na América Latina. A contentious politics começa a ser aplicada por aqui (por exemplo, Auyero, 2003), mas ainda em pequena escala. Já a teoria da sociedade civil herdou a hegemonia da TNMS na América Latina, orientando estudos acerca da autonomia dos atores da sociedade civil em relação às instituições políticas "tradicionais" (Foweraker, 2001) e de inovações políticas na participação deles em arenas decisórias e em experiências de democracia deliberativa (Costa, 1994; Avritzer, 1994; Alvarez, Escobar e Dagnino, 2000). Consequentemente, os estudos especificamente sobre movimentos sociais caíram significativamente na América Latina nesta virada de século ${ }^{13}$.

Ao mesmo tempo em que o debate abriu a angular do nacional para o global, focalizou a maneira como a cultura comparece nos processos de mobilização política. Abordagens do campo da sociologia da cultura, seja em chave pós-estruturalista, seja bourdiesiana, adentraram a conversa sobre o vínculo entre cultura e ação política. $O$ efeito foi atrair a polêmica sobre o próprio conceito de cultura para o coração dos embates entre as teorias da mobilização coletiva. Além de retornos a velhos conceitos, caso de "cultura política", é possível distinguir, grosso modo, cinco novas definições de cultura em uso no debate, que já não correspondem mais com precisão às três escolas teóricas sobre movimentos sociais dos anos 1970.

\footnotetext{
${ }^{13}$ Essa é a conclusão de um survey dos periódicos latino-americanos disponíveis eletronicamente, entre 2000 e 2006 (Alonso, Maciel, Salgado, 2007).
} 
A primeira e mais influente definição toma a cultura de uma perspectiva cognitiva. Vários autores se inspiraram na psicologia cognitiva para falar de esquematas, isto é, modelos mentais compartilhados, usados para perceber, processar e armazenar informações (DiMaggio, 1997, p. 5), que dariam as bases culturais para a mobilização. Nessa linha, Snow e Benford $(1986,1992,2000)$ redefiniram o conceito de frame de Erving Goffman como quadros interpretativos que simplificam e condensam o "mundo exterior", destacando, codificando e selecionando objetos, situações, acontecimentos, experiências e sequências de ações. Recorrendo à produção de frames, os movimentos sociais reduziriam a complexidade social a níveis manejáveis pelo indivíduo comum, sinalizando a injustiça de uma dada situação, vinculando-a a símbolos e apresentado-a como um problema que requer mobilização (Snow e Benford, 2000, p. 614). O conflito social passa aqui para o plano da definição da 78 realidade, isto é, disputas políticas são apresentadas como eminentemente simbólicas.

O conceito de frame enfatiza práticas interpretativas e o caráter construído e contingente dos significados que orientam mobilizações, aos quais faltaria, portanto, a organicidade de sistema suposta nos conceitos de ideologia e cultura política. Talvez por seu caráter alusivo, os frames foram acolhidos por todas as correntes, incorporados por Melucci (1996) e por Tarrow (1992), que os alargaram para masterframe, a fim de recobrir um ciclo inteiro de ativismo, e os usaram para tratar do ativismo internacional (Tarrow, 2005). Na mesma direção, Eyerman e Jamison (2003) usaram hinos e músicas de protesto como objeto empírico para explicitar a "práxis cognitiva” dos movimentos sociais.

Outra abordagem trabalha com uma noção performativa, privilegiando as práticas e a agency. A cultura é vista como terreno de litígio, perpassado por relações de poder. A ênfase está na intencionalidade dos agentes e em sua capacidade de 
recorrer seletivamente a repositórios passados de significados (os repertórios) para moldar estratégias de ação. Embora argumentos nessa direção se apresentem em Tilly, foi Ann Swidler (1986, 1995), inspirada em Bourdieu, quem trouxe a questão para o debate sobre movimentos sociais, ao formular a noção de "estratégias de ação". A cultura seria uma caixa de ferramentas, composta por símbolos, rituais e visões de mundo, que só adquiririam sentido pelo uso, isto é, quando mobilizados para orientar ações. A cultura se relaciona com a ação política em chave pragmática: como estruturadora dos processos de seleção, interpretação, reinvenção e uso intencional de significados por agentes uns contra outros, a partir de um repertório comum. O próprio Tilly (2008) acabou compelido a redefinir seu conceito de repertório. Inspirado em Goffman, adotou a metáfora teatral para descrever a relação entre agentes e repertórios, pondo a tônica na performance, isto é, no improviso e na interpretação a que os atores submetem um repertório quando agem ${ }^{14}$. Assim incorporou a agency, abrindo espaço para escolhas, interpretações e performances no interior de seu estruturalismo histórico.

Uma terceira embocadura privilegia a retórica dos ativistas e suas narrativas. Essa pegada pós-estruturalista chegou às teorias dos movimentos sociais em versão mitigada, como análise semântica de textos de militantes. A construção e disseminação de histórias seria condição para a emergência de movimentos sociais. Nelas, diz Poletta (2006), a realidade social é "arrumada" em enredos persuasivos, que dão aos ativistas um contexto de sentido e explicitam esquemas culturais e modelos de ação e interação, que possibi-

\footnotetext{
14 "A metáfora teatral chama a atenção para o caráter agrupado, aprendido, ainda que improvisado das interações das pessoas quando elas fazem e recebem as reivindicações umas das outras. Reivindicar usualmente se assemelha ao jazz e à commedia dell'arte mais do que à leitura ritual de textos sagrados. [...] Dentro desse ordenamento limitado, os atores escolhem quais peças vão encenar aqui e agora, e em qual ordem" (Tilly, 2008, p. 14).
} 
litam sua mobilização conjunta. Poletta advoga a conciliação dessa perspectiva com a TTP, defendendo a inclusão de memórias coletivas e normas culturais como elementos da estrutura de oportunidades políticas.

Um quarto ângulo, neodurkheimiano, trouxe para o debate sobre movimentos sociais a noção da cultura como moralidade e rituais de ação coletiva. Jeffrey Alexander (2006) e seu grupo de pesquisa investigam a formação de consensos simbólicos e sua expressão em revoluções, conflitos e eventos políticos, por meio do "comportamento expressivo motivado". As mobilizações políticas seriam assim rituais de encenação e atualização de significados socialmente compartilhados. Aí se abre nova porta para o retorno das emoções coletivas ao debate sobre movimentos sociais, desta vez do ângulo da performance e do drama.

Noutra chave, os afetos voltaram à explicação das mobilizações coletivas. Atacando as tradições de estudos dos movi80 mentos sociais como excessivamente racionalistas, Jasper (1997, 2007) abriu o campo para as "emoções do protesto", os sentimentos associados ao processo de conversão de indivíduos comuns em ativistas e aqueles suscitados durante os atos de protesto. As emoções seriam formas culturalmente construídas de compreender o mundo e exprimir posições. Sendo parte natural de todos os processos interpretativos, afetariam a compreensão da estrutura de oportunidades, de recursos e de frames. Processos emotivos, como o "choque moral", seriam detonadores da mobilização coletiva. Essas teses vêm sendo amplificadas (Emirbayer e Goldberg, 2005) e aplicadas a vários movimentos (Goodwin, Jasper e Polletta, 2001).

Como se vê, o conceito de cultura multiplicou seus sentidos no debate contemporâneo sobre movimentos sociais. Sem convergência à vista. Como Jasper (2007, p. 100) aponta em balanço da área, seguem abertas questões cruciais acerca da origem, da difusão, da mudança e das escolhas culturais e do modo pelo qual tudo isso se relaciona com a 
ação coletiva. Há várias propostas de conciliações teóricas, rumo a análises da ação coletiva que conjuguem cognição; agency; narrativas; rituais e emoções coletivas - caso do próprio Jasper -, mas, por ora, nenhuma delas parece persuasiva o bastante a ponto de ganhar o centro da cena.

O mesmo pode se dizer sobre a globalização do ativismo. Com tantas definições disponíveis e raríssimos estudos empíricos de escala efetivamente planetária, as teorias dos movimentos sociais estão também longe do consenso quando tratam de mobilizações "globais". Seguem ainda indemonstradas as fronteiras entre movimentos nacionais e globais. E promete dar pano para manga a conversa sobre a "novidade" do ativismo "global", como deu a celeuma sobre velhos e novos movimentos sociais. Disso é exemplar o provocador livro de Benedict Anderson (2007) sobre o caráter global do anarquismo - do século XIX.

Por sua importância empírica mais ou menos autoevidente na cena contemporânea e pela oferta tão generosa de teorias e definições, cultura e globalização são candidatas a permanecerem como as duas tópicas de maior relevo nas discussões sobre movimentos sociais nos próximos anos seguidas de perto pelo tema da violência. Mas daí a surgirem acordos teóricos acerca do seu significado é outra história.

\section{Angela Alonso}

é professora de sociologia da Universidade de São Paulo e pesquisadora do Cebrap

\section{Referências bibliográficas}

ALEXANDER, J. C. 1998. “Ação coletiva, cultura e sociedade civil. Secularização, atualização, inversão, revisão e desdobramento do modelo clássico dos movimentos sociais". RBCS, vol. 13, n 37 .

; GIESEN, B; MAST, J. 2006. Social performance: symbolic action, cultural pragmatics and ritual. Cambridge: Cambridge University Press. ALONSO, A.; MACIEL, D.; SALGADO, M. M. 2007. "Recent Latin-American and Brazilian studies on local-global activism”. DRC Working paper, May. 
ALVAREZ, S. E.; ESCOBAR, A. 1992. The making of social movements in Latin America: identity, strategy and democracy. Boulder: Westview Press, ; DAGNINO, E.; ESCOBAR, A. (orgs.). 2000. Cultura e política nos movimentos sociais latino-americanos: novas leituras. Belo Horizonte: Ed. UFMG.

ANDERSON, B. 1995. Under three flags: anarchism and the anti-colonial imagination. Rio de Janeiro: Verso.

ARATO, A.; COHEN, J. 1992. Civil society and political theory. Massachusetts /London: The MIT Press.

AUYERO, J. 2003. Contentious lives: two Argentine women, two protests, and the quest for recognition. Durham, North Carolina: Duke University Press.

AVRITZER, L. 1994. Sociedade civil e democratização. Belo Horizonte: Del Rey.

BENFORD, R. D.; DAVID, A. S. 2000. "Framing processes and social movements: an overview and assessment". Annual Review of Sociology, $\mathrm{n}^{\circ} 26$.

BOSCHI, R. 1987. A arte da associação. Política de base e democracia no Brasil. Rio de Janeiro: Iuperj/Vértice.

CALHOUN, C. 1995. "NNew social movements' of the early nineteenth century". In: TRAUGGOT, M. (ed.). Repertoires and cycles of collective action. Durham: Duke University Press.

82 CARDOSO, R. 1987. "Os movimentos sociais na América Latina”. RBCS, São Paulo, vol. 3, $\mathrm{n}^{\circ} 1$.

CASTELLS, M. 1996. The power of identity. The information age: economy, society and culture. Baltimore, Maryland: The Johns Hopkins University Press, vol. II.

CLARK, J. D. (eds.). 2003. Globalizing civic engagement: civil society and transnational action. London: Earthscan.

COHEN, J. 1985. "Strategy or identity: new theoretical paradigms and contemporary social movements". Social Research, vol. 52, nº 4 .

COSTA, S. 1994. "Esfera pública, redescoberta da sociedade civil e movimentos sociais no Brasil. Uma abordagem tentativa”. Novos Estudos Cebrap, n 38 , março.

DAVIS, D. 1999. "The power of distance: re-theorizing social movements in Latin America”. Theory and Society, vol. 28, $\mathrm{n}^{\circ}$ 4, pp. 585-638.

DIANI, M. 1992. "The concept of social movement". The Sociological Review, vol. $40, \mathrm{n}^{\circ} 1$.

2003. "Networks and social movements: a research programme”. In: DIANI, M.; MCADAM, D. (eds.). Social movements and networks. Relational approaches to collective action. Oxford: Oxford University Press. 
; McADAM, D. (eds.). 2003. Social movements and networks. Relational approaches to collective action. Oxford: Oxford University Press.

DIMAGGIO, P. 1997. "Culture and cognition". Annual Review of Sociology, $\mathrm{n}^{\circ} 23$.

EDELMAN, M. 2001. "Social movements: changing paradigms and forms of politics". Annual Review of Anthropology, $\mathrm{n}^{\circ} 30$.

EMIRBAYER, M. G.; CHAD, A. 2005. "Pragmatism, Bourdieu, and collective emotions in contentious politics". Theory and Society, vol. 34, $\mathrm{n}^{\circ}$ 5-6, December.

EYERMAN, R.; JAMISON, A. 2003. "Movements and cultural change". In: GODWIN, J.; JASPER, J. The social movements reader. Hoboken, NJ: Blackwell.

FALK, R. 1999. Predatory globalization. A critique. Cambridge: Polity Press.

FOWERAKER, J. 2001. "Grassroots movement and political activism in Latin America: a critical comparison of Chile and Brazil”. Latin American Studies, vol. 33, pp. 893-865.

GIUGNI, M. 1998. "Structure and culture in social movement theory". Sociological Forum, vol. 13, nº 2, June.

GOHN, M. G. 1997. Teoria dos movimentos sociais: paradigmas clássicos e contemporâneos. São Paulo: Edições Loyola.

GOODWIN, J.; JASPER, J.; POLLETTA, F. (eds.). 2001. Passionate politics. Emotions and social movements. Chicago: University of Chicago Press.

HABER, P. L. 1996. "Identity and political process: recent trends in the study of Latin American social movements". LARR, vol. 31, $\mathrm{n}^{\circ} 1$.

HABERMAS, J. 1981. "New social movements". Telos, New York, n 49. . 1984. Mudança estrutural da esfera pública. Rio de Janeiro: Tempo Brasileiro.

1987. “A nova intransparência”. Novos Estudos Cebrap, n ${ }^{\circ}$ 19, setembro.

HANNIGAN, J. A. 1985. "Alain Touraine, Manuel Castells and social movement theory. A critical appraisal”. The Sociological Quarterly, vol. 26, n 4.

INGLEHART, R. 1971. "The silent revolution in post-industrial societies". American Political Science Review, $\mathrm{n}^{\circ} 65$.

JASPER, J. 1997. The art of moral protest. Culture, biography, and creativity in social movements. Chicago: University of Chicago Press.

2007. "Cultural approaches in the sociology of social movements”. In: ROGGEBAND, C.; KLANDERMANS, B. (eds.). Handbook of social movement across disciplines. New York: Springer.

KEANE, J. 2003. Global civil society? Cambridge/New York: Cambridge University Press. 
KOWARICK, L. 1987. "Movimentos sociais urbanos no Brasil contemporâneo: uma análise da literatura”. $R B C S, \mathrm{n}^{\circ} 1(3)$.

KRIESI, H. et al. 1995. New social movements in Western Europe. London: ULC Press.

KURZMAN, C. 1997. "Structural opportunity and perceived opportunity in social movement theory: the Iranian revolution of 1979". In: McADAM, D.; SNOW, D. Social movements readings on their emergence, mobilization and dynamics. Los Angeles: Roxbury.

LYMAN, S. (ed.). 1995. Social movements. Critiques, concepts, case-studies. New York: NYU Press.

MARK, T. (ed.). 1995. Repertoires and cycles of collective action. Durham: Duke University Press.

McADAM, D. 1999. Political process and the development of black insurgency. Chicago: University of Chicago Press.

; McCARTHY, J.; ZALD, M. N. 1996. Comparative perspectives on social movements: political opportunities, mobilizing structures and cultural framings. Cambridge: Cambridge University Press.

.; TARROW, S.; TILLY, C. 2001. Dynamics of contention. New York: Cambridge University Press.

McCARTHY, J. D.; ZALD, M. N. 1977. "Resource mobilization and social movements: a partial theory”. American Journal of Sociology, vol. $82, \mathrm{n}^{\circ} 6$.

MELUCCI, A. 1980. "The new social movements: a theoretical approach". Social Science Information, vol. 19, $\mathrm{n}^{\circ} 2$.

. 1988. "Getting involved: identity and mobilization in social movements”. International Social Movements Research, vol. 1. 1989. Nomads of the present. Social movements and individual needs in contemporary society. Philadelphia: Temple University Press.

1996. Challenging codes: collective action in the information age. Cambridge: Cambridge University Press.

MORRIS, A. D.; MUELLER, C. M. (eds.) 1992. Frontiers in social movement theory. New Haven/London: Yale University Press.

MUELLER, C. M. 1992. "Building social movement theory". In: MORRIS, A. D.; MUELLER, C. M. (eds.) Frontiers in social movement theory. New Haven/London: Yale University Press.

PICHARDO, N. 1997. "New social movements: a critical review". Annual Review of Sociology, $\mathrm{n}^{\circ} 23$.

PIVEN, F. F.; CLOWARD, R. A. 1995. "Collective protest: a critique of resource-mobilization theory”. In: LYMAN, S. (ed.). Social movements. Critiques, concepts, case-studies. New York: NYU Press. 
PLOTKE, D. 1992. "What's so new about new social movements?". Socialist Review, $\mathrm{n}^{\circ}$ 46-87.

POLLETTA, F. 1999. "Snarls, quacks and quarrels: culture and structure in political process theory". Sociological Forum, vol. 14, n 1 , março. 2006. It was like a fever: storytelling in protest and politics. Chicago: Chicago University Press.

ROBERTS, K. M. 1997. "Beyond romanticism: social movements and the study of political change in Latin America”. Latin America Review, vol. $32, \mathrm{n}^{\circ} 2$.

ROGGEBAND, C.; KLANDERMANS, B. (eds). 2007. Handbook of social movement across disciplines. New York: Springer.

ROOTES, C. (ed.). 2003. Environmental protest in Western Europe. New York: Oxford University Press.

SADER, E. 1988. Quando novos personagens entram em cena. Rio de Janeiro: Paz e Terra.

SHEFNER, J. 2004. "Introduction: current trends in Latin American social movements". Mobilization: an International Journal, vol. 9, n 3 .

SNOW, D. et al. 1986. "Frame alignment processes, micromobilization, and movement participation". American Sociological Review, vol. 51.

SNOW, D. A.; BENFORD, R. D. 1992. "Master frames and cycles of protest”. In: MORRIS, A. D.; MUELLER, C. M. (eds.). Frontiers in social movement theory. New Haven London: Yale University Press.

SWIDLER, A. 1986. "Culture in action: symbols and strategies". American Sociological Review, vol. 51.

. 1995. "Cultural power and social movements". In: JOHNS-

TON, H.; KLANDERMANS, B. (eds). Social movements and culture. Minneapolis: University of Minnesota Press.

TARROW, S. 1992. "Mentalities, political cultures, and collective action frames”. In: MORRIS, A. D.; MUELLER, C. M. (eds.). Frontiers in social movement theory. New Haven/London: Yale University Press.

1998. Power in movement. Social movements and contentious politics. Cambridge: Cambridge University Press. . 2005. The new transnational activism. Cambridge: Cambridge University Press.

TILLY, C. 1978. From mobilization to revolution. Newberry Award Records. . 1993. "Contentious repertoires in Great Britain, 1758-1834". Social Science History, n ${ }^{\circ} 17$.

. 1995. "Contentious repertoires in Great Britain”. In: MARK, T. (ed.). Repertoires and cycles of collective action. Durham: Duke University Press. 

sity Press.

2008. Contentious performances. Cambridge: Cambridge Univer; TILLY, L.; TILLY, R. 1975. The rebellious century, 1830-1930. London: Dent.

TONI, F. 2001. "Novos rumos e possibilidades para os estudos dos movimentos sociais”. BIB - Boletim de Informação Bibliográfica da Anpocs, São Paulo, $\mathrm{n}^{\circ} 52,2^{\circ}$ semestre.

TOURAINE, A. 1978. La voix et le regard. Paris: Seuil. 1989a. Palavra e sangue. Política e sociedade na América Latina. Campinas: Ed. Unicamp. . 1989b. "Os novos conflitos sociais. Para evitar mal-entendidos". Lua Nova, $\mathrm{n}^{\circ}$ 17, junho, pp. 5-18.

TRAUGGOT, M. (ed.). 1995. Repertoires and cycles of collective action. Durham: Duke University Press.

ZALD, M. N. 1992. "Looking backward to look forward. Reflections on the past and future of the resource mobilization research program". In: MORRIS, A. D.; MUELLER, C. M. (eds.). Frontiers in social movement theory. New Haven/London: Yale University Press. 
AS TEORIAS DOS MOVIMENTOS SOCIAIS: UM BALANÇO DO DEBATE

\section{ANGELA ALONSO}

Este artigo apresenta as três principais teorias de explicação dos movimentos sociais, constituídas nos anos 1970; a Teoria de Mobilização de Recursos, a Teoria do Processo Político e a Teoria dos Novos Movimentos Sociais. Em seguida, mapeiam-se as reformulações de que essas teorias foram objeto, seja em reação às críticas recebidas, seja para fazer face às mudanças empíricas das últimas décadas, que acentuaram as dimensões cultural e transnacional do ativismo.

Palavras-chave: Teorias dos movimentos sociais; Mobilizações coletivas; Ativismo transnacional; Cultura e ação política.

\section{THE THEORIES OF SOCIAL MOVEMENTS: A REVIEW OF THE DEBATE}

This article presents the main theories on social movements raised in the 70's: the Resource Mobilization Theory, the Political Process Theory and the Theory of the New Social Movements. Then, the article discusses how those theories had to reshape themselves to face the criticisms they received as well as the empirical transformations the activism went through during the last decades, which stressed its cultural and transnational dimensions.

Keywords: Social movements' theories; Collective mobilizations; Transnational activism; Culture and political action. 